\title{
Air fungal contamination in two elementary schools in Lisbon, Portugal
}

\author{
C. Viegas ${ }^{1}$, C. Veríssimo ${ }^{2}$, L. Rosado ${ }^{2}$ \& C. Silva Santos ${ }^{3}$ \\ ${ }^{1}$ Higher School of Health Technologies of Lisbon, \\ Polytechnic Institute of Lisbon, Portugal \\ ${ }^{2}$ National Institute of Health Dr. Ricardo Jorge, \\ Mycology Laboratory, Portugal \\ ${ }^{3}$ School of Public Health, New University of Lisbon, Portugal
}

\begin{abstract}
A descriptive study was developed to monitor air fungal contamination in two elementary schools in Lisbon, Portugal. Eight air samples of 250 litres through impaction method were collected in the canteen, library, classrooms and also, outside premises as a reference place. Simultaneously, environmental parameters were also monitored, including temperature, and humidity through the equipment Babouc, LSI Systems and according to the International Standard ISO 7726 1998.

Considering both schools, sixteen different species of fungi in the air were identified, the two most commonly isolated being Cladosporium sp. $(51,1 \%)$ and Penicillium sp. (27,5\%). Besides these genera Trichoderma, Aspergillus, Alternaria, Chrysonilia, Botritys, Ulocladium, Athrium, Aureobasidium, Phoma, Scedosporium e Geotrichum were also isolated. Regarding yeasts, Candida sp., Cryptococcus sp. and Rhodotorula sp. were isolated. The youngest school, as well the canteens in each school, presented the worst results concerning the air fungal contamination, maybe due to the higher number of occupants.

There was no significant relationship $(p>0,05)$ between fungal contamination and temperature and humidity.
\end{abstract}

Keywords: air, fungal contamination, elementary schools, comparison. 


\section{Introduction}

Exposure effects to fungi are dependent on the species present, the metabolic products, concentration and duration of exposure, and also individual susceptibility [1]. Fungal exposures in schools are of particular interest because of the occupants' age and susceptibility and also the possibility of long term health outcomes such as the development of sensitivities, asthma [2] or other effects attributed to mycotoxin exposures [3, 4].

Despite the possibility of adverse health effects due to exposure to fungal products, no health-based exposure limits have yet been proposed. In part, this is due to the difficulty of accurately characterizing cumulative fungal spore concentrations [5] and also because, until now, epidemiological studies have failed to establish a causal relationship of the extent of fungal presence, exposure time and specific effects on health or frequency and severity of symptoms reported. Studies tend to show only the existence of a link between exposure to fungi and the development of symptoms, especially respiratory symptoms [1]. Attempts have been made only to identify fungi responsible for specific symptoms, such as allergenic [6], inflammatory [7] or mycotoxic [8] attributed to mold exposures.

Also worth mentioning is the importance of recognizing the environmental variables that influence air fungal contamination. Ozkutuk et al. found a significant association between the increasing age of buildings and the presence of some fungal species such as those belonging to the genus Aspergillus [9]. Studies on fungal spread in indoor environments evidence the presence of high levels of humidity. Moreover, most fungal species need moisture levels above $75 \%$ to grow, therefore justifying its development in kitchens and toilets [10]. A study conducted revealed peaks of fungal spores in the outside air, with temperatures of between $22^{\circ} \mathrm{C}$ and $27^{\circ} \mathrm{C}$ and humidity between 75 and $80 \%$, and smaller quantities of fungal spores with temperatures of between $43^{\circ} \mathrm{C}$ and $48^{\circ} \mathrm{C}$ and humidity between 25 and 40\% [11]. Moreover, Wong et al. and Strachan et al. also found an air fungal contamination increase with high values of temperature and humidity $[12,13]$.

In Portugal, in recent years, the prevalence of diseases such as asthma and rhinoconjunctivitis with values from $15 \%$ to $25 \%$ and from $10 \%$ to $15 \%$, respectively, in the general population has increased [14]. Various causes have been considered, including indoor air pollution caused by fungal contamination. Therefore, it is important to contribute to the increase of knowledge referring air fungal contamination in indoor spaces, such as elementary schools, and the environmental variables influence, in order to identify the most effective preventive measures to avoid such contamination.

This investigation was designed to monitor air fungal contamination in two elementary schools, and explore possible associations with independent environmental variables. 


\section{Materials and methods}

A descriptive study was developed to monitor air fungal contamination in two elementary schools, one being 9 years and the other being 30 years old. Eight air samples of 250 litres through impaction method were collected. Air samples were collected in the canteen, library, classrooms and also, outside premises, since this is the place regarded as a reference. Simultaneously, environmental parameters were also monitored, including temperature, and humidity through the equipment Babouc, LSI Systems and according to the International Standard ISO $7726-1998$.

Air samples were collected at $140 \mathrm{~L} /$ minute and at one meter tall using malt extract agar with chloramphenicol as a bacteria growth inhibitor (MEA), in the facilities and also outside premises, since this is the place regarded as a reference. Subsequently, samples were incubated at $27^{\circ} \mathrm{C}$ for 5 to 7 days.

After laboratory processing and incubation of the collected samples, quantitative $\left(\mathrm{CFU} / \mathrm{m}^{3}\right)$ and qualitative results were obtained, with identification of isolated fungal species. Whenever possible, filamentous fungi were identified to the species level, since adverse health effects vary according to fungal species $[15,16]$. Identification of filamentous fungi was carried out on material mounted in lactophenol blue and achieved through morphological characteristics listed in illustrated literature [16]. Yeasts were identified through biochemical API test [17].

With the obtained data, tables with frequency distribution of isolated fungal species were made. Fungal concentration dependence in the two monitored environmental parameters - temperature and relative humidity - was also analyzed.

\section{Results}

Considering both schools, sixteen different species of fungi in the air were identified, the two most commonly isolated being Cladosporium sp. $(51,1 \%)$ and Penicillium sp. (27,5\%). Besides these genera Trichoderma, Aspergillus, Alternaria, Chrysonilia, Botritys, Ulocladium, Athrium, Aureobasidium, Phoma, Scedosporium e Geotrichum were also isolated. Regarding yeasts, Candida sp., Cryptococcus sp. and Rhodotorula sp. were isolated.

In both schools, Cladosporium was the most frequent genera (youngest school: 52,8\%; oldest school: 47,6\%) followed by Penicillium genera (youngest school: $28,0 \%$; oldest school: $26,2 \%$ ). The youngest school presented 8 different genera and the oldest presented 11 different genera (Table 1).

All the indoor spaces from both schools presented fungal species different from the ones isolated outdoors. Some fungi that were only isolated indoors were: Trichoderma, Aspergillus flavus, Aspergillus niger, Aspergillus ochraceus, Scedosporium prolificans, Ulocladium sp., Athrium sp., Aureobasidium sp., Phoma, sp., Geotrichum candidum, Candida sp., Cryptococcus sp., and Rhodotorula sp. 
Table 1: $\quad$ Most frequent fungi identified in both schools.

\begin{tabular}{|c|c|}
\hline Youngest school & Frequency (\%) \\
\hline Cladosporium sp. & 52,8 \\
Penicillium sp. & 28,0 \\
Trichoderma sp. & 5,6 \\
Alternaria sp. & 3,3 \\
Chrysonilia sp. & 3,3 \\
Aspergillus sp. & 3,3 \\
Others & 3,7 \\
\hline Oldest school & Frequency (\%) \\
\hline Cladosporium sp. & 47,6 \\
Penicillium sp. & 26,2 \\
Alternaria sp. & 2,4 \\
Aspergillus sp. & 2,4 \\
Aureobasidium sp. & 2,4 \\
Phoma sp. & 2,4 \\
Others & 9,6 \\
\hline
\end{tabular}

Concerning quantitative results, the highest fungal contamination found indoors was, in the youngest school $216 \mathrm{CFU} / \mathrm{m}^{3}$, and in the oldest school $92 \mathrm{CFU} / \mathrm{m}^{3}$. Both schools presented the highest fungal contamination in canteens. Regarding comparison of concentrations found for indoor and exterior environments; in the oldest school only in canteen indoor monitoring presented more $\mathrm{CFU} / \mathrm{m}^{3}$ than the one carried out outdoors. However, in the youngest

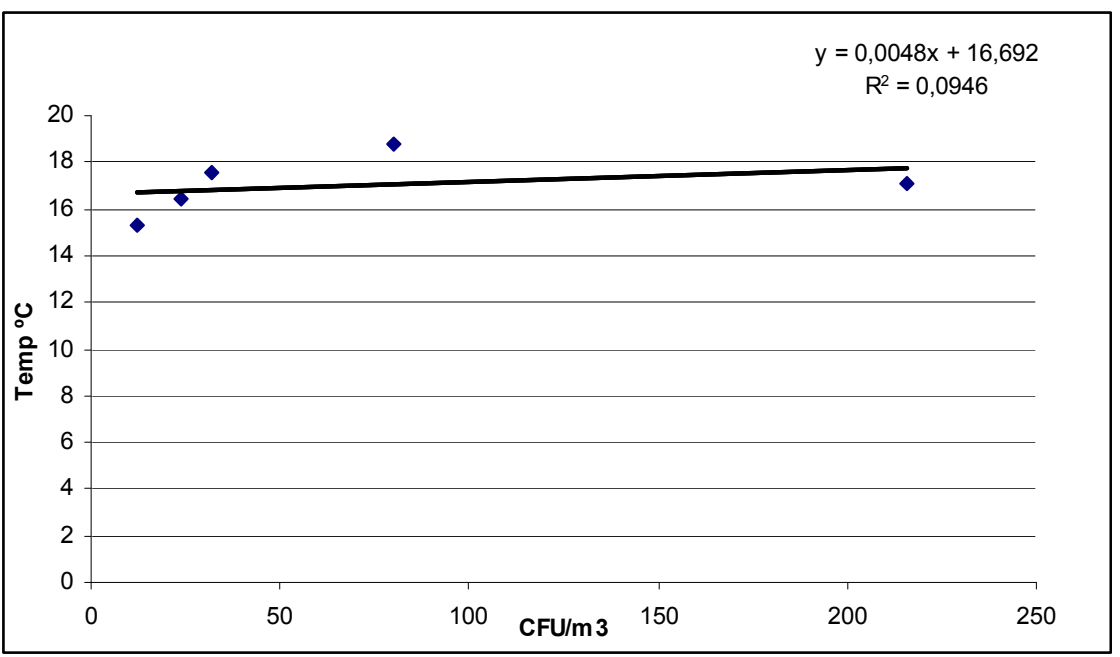

Figure 1: Influence of temperature in $\mathrm{CFU} / \mathrm{m}^{3}$. 
school all indoor areas monitored showed more $\mathrm{CFU} / \mathrm{m}^{3}$ than the monitoring carried out outdoors.

Regarding the influence of environmental variables monitored, no significant correlation $(p>0,05)$ was revealed in both elementary schools. For instance in the youngest school, temperature and relative humidity contributed only in $9,46 \%$ and $2,44 \%$, respectively, to $\mathrm{CFU} / \mathrm{m}^{3}$ variation explanation (Figures 1 and 2).

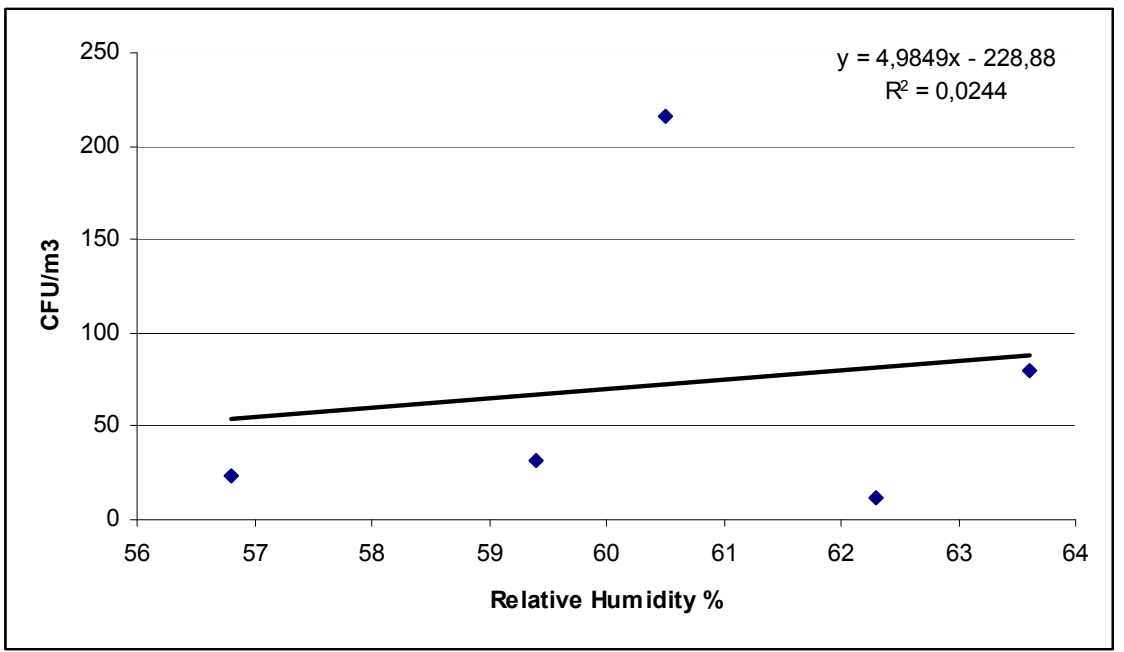

Figure 2: Influence of relative humidity in $\mathrm{CFU} / \mathrm{m}^{3}$.

\section{Discussion}

Cladosporium genus, the predominant type in both schools, is probably the fungus that occurs more frequently around world, especially in temperate climates [18] such as Portugal. The same genus is deeply connected to indoor condensation problems [19]. For Penicillium sp., the second genera more predominant also in both schools, there are different potential risks associated with their inhalation, due to the toxins release.

With regard to a qualitative assessment of fungal contamination in air, it is suggested that, among other species, Penicillium, Trichoderma and Ulocladium species, all of them isolated in the present study, are regarded as indicators of humidity problems or potential risk to health [1]. Moreover, according to the American Industrial Hygiene Association (AIHA) in 1996, for the determination of biological contamination in environmental samples, the confirmed presence of Aspergillus flavus, identified in the youngest school, requires implementation of corrective measures [20]. In addition, Aspergillus flavus is a well-known producer of potent mycotoxins (aflatoxins) and besides this species other isolated genera, like Penicillium, is also known as mycotoxins producer [20]. 
For a quantitative assessment in air, $\left(\mathrm{CFU} / \mathrm{m}^{3}\right)$ is proposed corrective measures implementation whenever, in a given space, one or more of the following conditions were verified: a) $>50 \mathrm{CFU} / \mathrm{m}^{3}$ of a single fungal species; b) $>150 \mathrm{CFU} / \mathrm{m}^{3}$ if several fungal species are isolated; c) $>300 \mathrm{CFU} / \mathrm{m}^{3}$ if there are mainly filamentous fungi [21]. The first condition - a) - was found for Cladosporium sp. and Penicillium sp., being Cladosporium genera in both schools, and for Penicillium genera only in the youngest school. The second condition - b) - was found only in the youngest school canteen.

Moreover, it is suggested that fungal levels found indoors should be compared, quantitatively and qualitatively, with those found on the exterior, because the first are dependent on the last [1]. Thus, indoor air quality that is significantly different from one outdoors could mean that there are infiltration problems and potential health effects. In this study, with regard to quantitative comparison, in the oldest school only in the canteen did indoor monitoring present more $\mathrm{CFU} / \mathrm{m}^{3}$ than the one carried out outdoors. However, in the youngest school all indoor areas monitored showed more $\mathrm{CFU} / \mathrm{m}^{3}$ than the monitoring carried out outdoors.

Taking into account what is mentioned in Portuguese law, $500 \mathrm{CFU} / \mathrm{m}^{3}$ maximum reference concentration in interior air was not exceeded in any of the monitored spaces, because the highest fungal contamination found indoors was, in the youngest school $216 \mathrm{CFU} / \mathrm{m}^{3}$, and in oldest school $92 \mathrm{CFU} / \mathrm{m}^{3}$.

Also worth mentioning is the fact that outdoor air is a major source of fungi in indoors, thus justifying the coincidence between Cladosporium genera in both these environments in the two schools [22]. Nonetheless, all monitored interior spaces, in both schools, had fungal species different from the ones isolated outside, suggesting fungal contamination from within [23].

Despite Ozkutuk et al. having found a significant association between the increasing age of buildings and the presence of some fungal species such as Aspergillus genera [9], the youngest school presented the highest fungal contamination, more indoor areas with higher $\mathrm{CFU} / \mathrm{m}^{3}$ values than the outdoors, and also a Aspergillus sp. superior isolation frequency (Table 1). This situation may be due to the higher number of occupants, namely teachers and children, who may carry, in their own body (commensal flora) or clothing, a great diversity of fungal species [24]. The same reason can justify why canteens presented the highest fungal contamination in both schools.

It was found that the relationship between the fungal air contamination and the temperature and relative humidity was not statistically significant $(p>0,05)$ in both schools, despite results obtained from others studies [12, 13]. This may be justified by the effect of other environmental variables also influencing fungal spreading, namely the occupants' number [24], as well the developed activities that may also affect fungal concentration [25].

\section{Conclusions}

It was possible to characterize fungal distribution in two elementary schools and evaluate the association of environmental variables with this distribution. The 
youngest school, as well as the canteens in each school, presented the worst results concerning air fungal contamination, may be due to the higher number of occupants.

Unlike other studies, environmental variables monitored (temperature and relative humidity) did not show the expected association with fungal concentration, which may possibly have resulted from other variables not investigated in this study.

\section{References}

[1] Goyer N, Lavoie J, Lazure L \& Marchand G., Bioaerosols in the Workplace: Evaluation, Control and Prevention Guide. Institut de Recherche en Santé et en Sécurité du Travail du Québec, 2001.

[2] Taskinen T, Hyvaryen A, Meklin T, Husman T, Nevalainen A \& Korppi M., Asthma and respiratory infections in school children with special reference to moisture and mold problems in the school. Acta Paediat, 88, pp., 1373 - 1379, 1999.

[3] Dales R, Miller D, White J, Dulberg C \& Lazarovits A., Influence of residential fungal contamination on peripheral blood lymphocyte populations in children. Arch Environ Health, 53, pp., 190 - 196, 1998.

[4] Savilahti R, Uitti J, Laippala P, Husman T \& Roto P., Respiratory morbidity among children following renovation of a water-damaged school. Arch Environ Health, 55, pp., 406 - 411, 2000.

[5] Bartlett K, Kennedy S, Brauer M, Van Netten C \&Dill B., Evaluation and predictive model of airborne fungal concentrations in school classrooms. Ann Occup Hyg, 48, pp., 547 - 554, 2004.

[6] Cruz A, Saenz de Santamaria M, Martinez J, Martinez A, Guisantes J \& Palácios R., Fungal allergens from important allergenic fungi imperfecti. Allergol Immunopathol, 25, pp., 153 - 158, 1997.

[7] Rylander R, Persson H, Goto H, Yuasa K \& Tanaka S., Airborne beta (1,3)glucans may be related to symptoms of sick buildings. Indoor Environment, 1, pp., $263-267,1992$.

[8] Hodgson M, Morey P, Leung W, Morrow L, Miller D, Jarvis B, Robbins H, Halsey J \& Storey E., Building associated pulmonary disease from exposure to Stachybotrys chartarum and Aspergillus versicolor. J Occup Environm Med, 40, pp., 241 - 249, 1998.

[9] Ozkutuk A, Ceylan E, Ergor G, Yucesoy M, Itil O, Caymaz S \& Cimrin A., The relationship between moulds isolated from indoor air and features of the house environment. Indoor and Built Environment, 17, 3, pp. 269 - 273, 2008.

[10] Arundel A, Sterling E, Biggin J \& Sterling T., Indirect Health Effects of Relative Humidity in Indoor Environments. Environmental Health Perspectives, 65, pp. $351-361,1986$.

[11] Kakde U, Kakde H \& Saoji A., Seasonal Variation of Fungal Propagules in a Fruit Market Environment, Nagpur (India). Aerobiologia, 17, pp. 177 $182,2001$. 
[12] Wong L, Mui K, Hui P, Chan W, Law A., Thermal environmental interference with airborne bacteria and fungi levels in air-conditioned offices. Indoor and Built Environment, 17, 2, pp. 122 - 127, 2008.

[13] Strachan D, Flannigan B, Mccabe E \& Mcgarry F., Quantification of airborne moulds in the homes of children with and without wheeze. Thorax, 45 , pp. $382-287,1990$.

[14] Nunes C \& Ladeira S., Estudo da Qualidade de Ambiente Fúngico em Escolas e Edifícios Públicos no Algarve. Revista Portuguesa Imunoalergologia, 15, pp. $411-422,2007$.

[15] Rao C, Burge H \& Chang J., Review of quantitative standards and guidelines for fungi in indoor air. J Air Waste Manage Assoc., 46, pp. 899 908, 1996.

[16] Hoog C, Guarro J, Gené G \& Figueiras M., (2 $2^{\text {th }}$ ed). Atlas of Clinical Fungi. Centraalbureau voor Schimmelcultures, 2000.

[17] Ghannoum M, Hajeh R, Scher R, Konnikov N, et al., A large-scale North American study of fungal isolates from nails: The frequency of onychomycosis, fungal distribution and antifungal susceptibility patterns. $J$. Am. Acad. Dermatol, 43, pp. 641 - 648, 2000.

[18] Cooley J, Wong W, Jumper C \& Straus D., Correlation between the prevalence of certain fungi and sick building syndrome. Occup. Environ Med, 55, pp., 579 - 584, 1998.

[19] Garret M, Rayment P, Hooper M, Abranson M \& Hooper B., Indoor Airborne Fungal Spores, House Dampness and Associations with Environmental Factors and Respiratory Health in Children. Clinical and Experimental Allergy, 28, pp., 459 - 467, 1998.

[20] American Industrial Hygiene Association: Field Guide for the Determination of Biological Contaminants in Environmental Samples. AIHA, 1996.

[21] Miller J., Fungi as Contaminants of Indoor Air. Atmos. Environm, 26 A, pp., 2163 - 2172, 1992.

[22] Nevalainen A., Bio-aerosols as exposure agents in indoor environment in relation to asthma and allergy. Section 3 Asthma and allergy. Proceedings of the First ENVIE Conference on Indoor Air Quality and Health for EU Policy, Helsinki, Finland, 2007.

[23] Kemp P, Neumeister-Kemp H, Murray F \& Lysek G., Airborne fungi in non-problem buildings in a southern-hemisphere Mediterranean climate: preliminary study of natural and mechanical ventilation. Indoor and Built Environment, 11; pp., 44 - 53, 2002.

[24] Scheff P, Pulius V, Curtis L \& Conroy L., Indoor air quality in a middle school, Part II: Development of emission factors for particulate matter and bioaerosols. Applied Occupational and Environmental Hygiene, 15, pp. 835 $-842,2000$.

[25] Buttner M \& Stetzenbach L., Monitoring Airborne fungal spores in an experimental indoor environment to evaluate sampling methods and the effects of human activity on air sampling. Applied and Environmental Microbiology, 59, pp. 219-226, 1993. 